\title{
A model for two-step ageing
}

\author{
K T KASHYAP*, C RAMACHANDRA, B CHATTERJI and S LELE ${ }^{\dagger}$ \\ Central Materials and Processes Laboratory, Foundry \& Forge Division, Hindustan Aeronautics Limited, \\ Bangalore 560 017, India \\ *Department of Metallurgical Engineering, Banaras Hindu University, Varanasi 221 005, India
}

MS received 24 January 2000; revised 4 May 2000

\begin{abstract}
In commercial practice, two-step ageing is commonly used in Al-Zn-Mg alloys to produce a fine dispersion of $\eta^{\prime}$ precipitates to accentuate the mechanical properties and resistance to stress corrosion cracking. While this is true in Al-Zn-Mg alloys, two-step ageing leads to inferior properties in Al-Mg-Si alloys. This controversial behaviour in different alloys can be explained by Pashley's Kinetic model. Pashley's model addresses the stability of clusters after two-step ageing. In the development of the model, the surface energy term between cluster and matrix is taken into account while the coherency strains between the cluster and matrix are not considered. In the present work, a model is developed which takes into account the coherency strains between cluster and matrix and defines a new stability criterion, inclusive of strain energy term. Experiments were done on AA 7010 aluminium alloy by carrying out a two-step ageing treatment and the results fit the new stability criterion. Thus it is found that the new model for two-step ageing is verified in the case of Al-Zn-Mg alloy.
\end{abstract}

Keywords. Two-step ageing; delayed ageing; clusters; coherency strains.

\section{Introduction}

In $\mathrm{Al}-\mathrm{Zn}-\mathrm{Mg}$ alloys, preageing at a lower temperature after solutionizing, followed by a higher temperature artificial ageing is known to give a fine dispersion of $\eta^{\prime}$ precipitates (Lorimer and Nicholson 1966) and thus enhance the mechanical properties. While this is true in $\mathrm{Al}-\mathrm{Zn}-\mathrm{Mg}$ alloys, in $\mathrm{Al}-\mathrm{Mg}-\mathrm{Si}$ alloys, room temperature storage after solutionizing, followed by high temperature artificial ageing leads to a coarse precipitate $\left(\beta^{\prime}\right)$ structure (Pashley et al 1966). This phenomenon is termed delayed ageing wherein the delay after solutionizing before ageing leads to inferior properties (Ghate et al 1984; Murali et al 1993).

Pashley et al have put forth a kinetic model to describe the stability of clusters after two-step ageing, which qualitatively explains the controversy between $\mathrm{Al}-\mathrm{Zn}-\mathrm{Mg}$ and $\mathrm{Al}-\mathrm{Mg}-\mathrm{Si}$ alloys. In Pashley's kinetic model, a parameter $K$ is defined which is proportional to the surface energy between the cluster and matrix which determines the stability of distribution of clusters in two-step ageing. In the case of $\mathrm{Al}-\mathrm{Zn}-\mathrm{Mg}$ alloys, fine scale seeding takes place at a lower temperature ageing which gets stabilized at higher temperature ageing resulting in a fine dispersion of $\eta^{\prime}$ precipitates. However in $\mathrm{Al}-\mathrm{Mg}-\mathrm{Si}$ alloys only the coarse clusters are stabilized at the artificial ageing tem-

\footnotetext{
*Author for correspondence
}

perature and this leads to a coarse distribution of $\beta^{\prime}$ precipitates.

While Pashley's kinetic model addresses the surface energy between the cluster and the matrix, the elastic coherency strains between them are not considered. Therefore it is the objective of the present work to include coherency strains between the cluster and matrix in the development of the Pashley's kinetic model (extended Pashley's model) and verify the same.

\section{The model}

In the present model, elastic strains between the cluster and matrix are considered. The elastic strains are introduced via the classical definition of Gibbs free energy. Thus the Gibbs-Thomson relationship is modified in that not only the curvature effect is considered in terms of the partial molar free energy but also elastic strain energy is included. The Gibbs-Thomson relationship is the one that describes the solubility as a function of curvature of an interface. Here only the surface energy and curvature have an influence on solubility. In the modified GibbsThomson relationship not only the curvature and surface energy have an influence on the solubility but also the elastic strain energy. Using the modified Gibbs-Thomson relationship, the criterion for the stability of the clusters is derived for two-step ageing. Further, it is also assumed that the elastic modulus of the cluster is greater than that 
of the matrix and therefore the coherency strains are accommodated in the matrix.

It is known from classical thermodynamics (Fast 1970), that Gibbs free energy can be expressed as

$$
G=U-T S+\sum X Y
$$

where $G$ is the Gibbs free energy, $U$, the internal energy, $S$, entropy, $T$, absolute temperature, $\sum X Y$ the work done due to elastic strains, thus $\sum X Y$ can be expressed as two terms viz. volume work $(P d V)$ and work done due to elastic strains, thus

$$
G=U-T S+P V+V_{\mathrm{m}} \dot{O}\left(\frac{\stackrel{\circ}{2}}{2}\right),
$$

$V_{\mathrm{m}}$ is molar volume, $\sigma$, stress in the matrix which is elastic.

Differentiating (2), we have

$$
d G=d U-T d S-S d T+P d V+V d P+\frac{V_{\mathrm{m}}}{2} o ́ d \stackrel{V_{\mathrm{m}}}{2} \stackrel{a}{d} d o .
$$

Assuming reversibility, the term $d U$ can be expressed as

$$
d U=T d S-P d V-\frac{V_{\mathrm{m}}}{2} \delta \dot{d} .
$$

Substituting (4) in (3)

$$
d G=V d P+\frac{V_{\mathrm{m}}}{2} \stackrel{\circ}{a} d o-S d T .
$$

At constant temperature $(d T=0)$,

$$
d G=V d P+\frac{V_{\mathrm{m}}}{2} \stackrel{\circ}{d} d o
$$

Assuming the elastic strains to be small, i.e. Hooke's law is valid,

$$
\sigma=E \varepsilon
$$

where $E$ is the Young's modulus,

$$
d \sigma=E d \varepsilon
$$

Substituting (6) in (5),

$$
d G=V d P+\frac{V_{\mathrm{m}}}{2} \varepsilon E d \varepsilon
$$

Expressing the above relationship in terms of partial quantities,

$$
d \bar{G}_{\mathrm{i}}=\bar{V}_{\mathrm{m}} d P+\frac{\bar{V}_{\mathrm{m}}}{2} \stackrel{\circ}{\mathrm{a}} \mathrm{d} d \varepsilon .
$$

Integrating (7) for a curved interface,

$$
\begin{aligned}
\bar{G}_{\mathrm{i}, \mathrm{r}}-\bar{G}_{\mathrm{i}, \infty} & =V_{\mathrm{m}}\left(P_{\mathrm{r}}-P_{\infty}\right)+\frac{V_{\mathrm{m}} E \dot{a}^{2}}{4}, \\
& =V_{\mathrm{m}} \Delta P+\frac{V_{\mathrm{m}} E \varepsilon^{2}}{4},
\end{aligned}
$$

where, $G_{\mathrm{i}, \mathrm{r}}$ is the partial molar free energy of a curved interface of radius ' $\mathrm{r}$ ', $G_{\mathrm{i}, \infty}$ the partial molar free energy of a flat interface and $P_{\mathrm{r}}, P_{\infty}$ are pressures across a curved interface and a flat interface respectively.

It is known from classical thermodynamics (Fast 1970) that

$$
\bar{G}_{\mathrm{i}, \mathrm{r}}-\bar{G}_{\mathrm{i}, \infty}=R T \ln \left(\frac{a_{\mathrm{i}, \mathrm{r}}}{a_{\mathrm{i}, \infty}}\right)
$$

Combining (9) and (8a), where $a_{\mathrm{i}, \mathrm{r}}, a_{\mathrm{i}, \infty}$ are the activity of the solute in a curved interface and flat interface, respectively

$$
R T \ln \left(\frac{a_{\mathrm{i}, \mathrm{r}}}{a_{\mathrm{i}, \infty}}\right)=\bar{V}_{\mathrm{m}} \tilde{a}\left(\frac{1}{r_{1}}+\frac{1}{r_{2}}\right)+\frac{V_{\mathrm{m}} E \dot{a}^{2}}{4} .
$$

Since

$$
\Delta P=\gamma\left(\frac{1}{r_{1}}+\frac{1}{r_{2}}\right)
$$

where, $\gamma$ is the surface energy and $r_{1}, r_{2}$, are the principal radii of curvature (Porter and Easterling 1992).

Assuming ideal solution behaviour,

$$
a_{\mathrm{i}}=X_{\mathrm{i}}
$$

where $X_{\mathrm{i}}$ is the concentration,

$$
R T \ln \left(\frac{X_{\mathrm{i}, \mathrm{r}}}{X_{\mathrm{i}, \infty}}\right)=V_{\mathrm{m}} \tilde{a}\left(\frac{1}{r_{1}}+\frac{1}{r_{2}}\right)+\frac{V_{\mathrm{m}} E \dot{a}^{2}}{4} .
$$

Assuming spherical clusters (it is believed that the physical reasoning behind the model is not altered because of the cluster shape)

$$
\begin{aligned}
& \ln \left(\frac{X_{\mathrm{i}, \mathrm{r}}}{X_{\mathrm{i}, \infty}}\right)=\left(\frac{V_{\mathrm{m}} \gamma(2)}{R T r}+\frac{V_{\mathrm{m}} E \varepsilon^{2}}{4 R T}\right), \\
& X_{\mathrm{i}, \mathrm{r}}=X_{\mathrm{i}, \infty}\left(\exp \left(\frac{V_{\mathrm{m}} 2 \gamma}{R T r}+\frac{V_{\mathrm{m}} E \varepsilon^{2}}{4 R T}\right)\right) .
\end{aligned}
$$

This is the modified Gibbs-Thomson relationship where not only curvature has an effect on the solubility but also strains between the cluster and matrix. 
In the original Pashley's model (Pashley et al 1967), the stability of the clusters is dictated by the condition that the rate of arrival of solute to the cluster should be greater than the rate of departure of solute from the cluster.

Pashley et al (1967) have given the condition to be

$$
A X_{\infty} S>B X
$$

where, $A$ is the coefficient which determines the rate of arrival of solute to the clusters which is proportional to the diffusion coefficient and excess vacancies. $S$ is the supersaturation $=W(1-\alpha) / X_{\infty}, W$, being the weight of the solute/unit volume, $\alpha$ the fraction of solute in the clusters. $X_{\infty}$, concentration of the solute in equilibrium with a flat interface, $X$, concentration of the solute in equilibrium with a curved interface and $B$, the kinetic coefficient.

The Gibbs-Thomson relationship without elastic strains is

$$
X_{\mathrm{i}, \mathrm{r}}=X_{\mathrm{i}, \infty} \exp \left(\frac{V_{\mathrm{m}} 2 \gamma}{R T r}\right) .
$$

Substituting (13) in (12) for $X$, Pashley arrived at the stability criterion,

$$
\begin{aligned}
& A X_{\infty}>B X_{\mathrm{i}, \infty} \exp \left(\frac{V_{\mathrm{m}} 2 \gamma}{R T r}\right), \\
& \text { i.e. } \quad r \ln \left(\frac{A}{B}\right) S>\left(\frac{V_{\mathrm{m}} 2 \gamma}{R T}\right) .
\end{aligned}
$$

Letting,

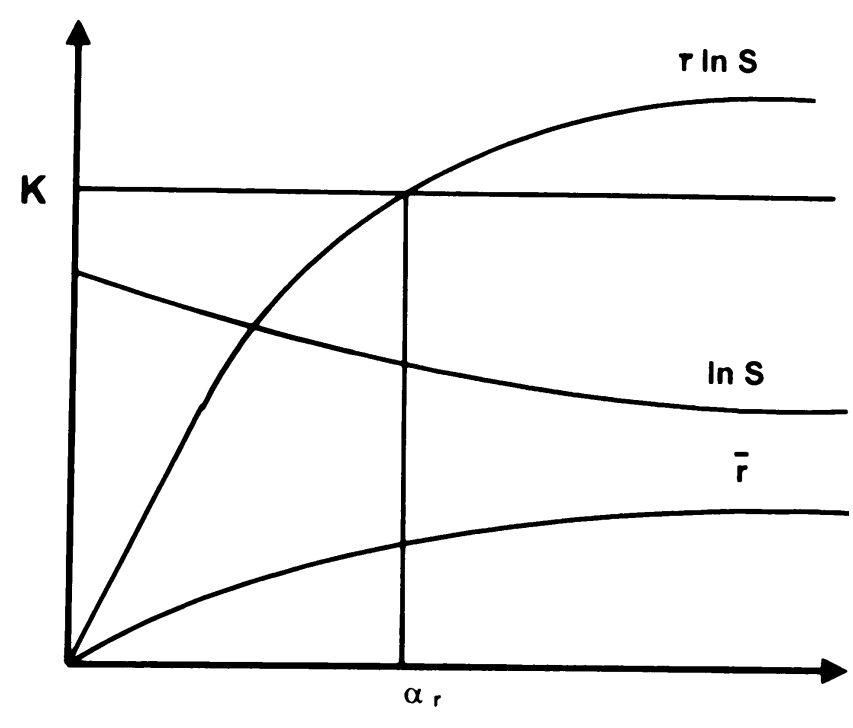

FRACTION OF SOLUTE IN CLUSTERS - $\alpha$

Figure 1. Schematic illustration of stability of clusters in twostep ageing.

$$
K=\frac{V_{\mathrm{m}} 2 \gamma}{R T}
$$

(14) becomes

$$
r \ln \left(\frac{A}{B}\right) S>K .
$$

If it is assumed that no excess vacancies are present, $A=B$, (15) becomes

$$
r \ln S>K
$$

This is the stability criterion in the original Pashley's model.

Furthermore, assuming spherical clusters, mass balance of the solute leads to the following

$$
\sum \frac{4}{3} \pi r^{3} \rho n_{\mathrm{r}}=\alpha W
$$

where, $\rho$ is the density of the cluster species, $n_{\mathrm{r}}$, the number of cluster per unit volume.

Figure 1 shows these relationships schematically, with a delay at a lower temperature $\left(T_{1}\right), \alpha$ increases and supersaturation in the matrix decreases and when $\alpha>\alpha_{r}$, the clusters are stabilized at the artificial ageing temperature $\left(T_{2}\right)$.

Figure 2 shows the effect of size distribution of clusters on the stability after two step-ageing. At a lower temperature $\left(T_{1}\right)$, clustering will take place resulting in a size distribution of clusters. The size distribution can be assumed to be gaussian and accordingly the variation of $r$

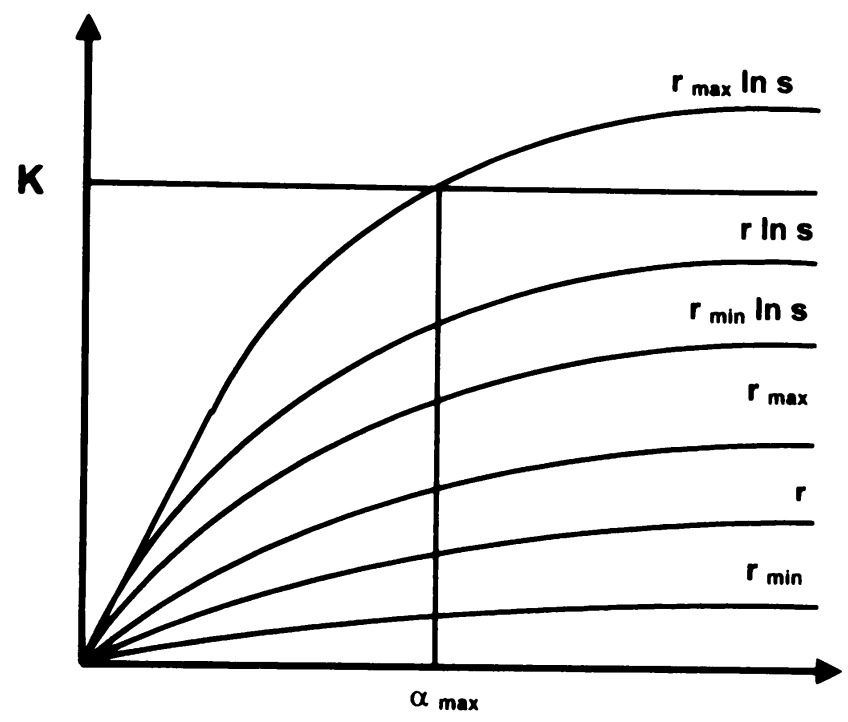

FRACTION OF SOLUTE IN CLUSTERS - $\alpha$

Figure 2. Schematic illustration of stability of clusters with size distribution in the original model. 
with $\alpha$ can be represented as shown in figure 2 . In a similar way the term $r \ln S$ is also shown in figure 2. It is seen that when $\alpha>\alpha_{r \max }$, only the coarse clusters are stabilized at the artificial ageing temperature $\left(T_{2}\right)$ after a delay at the lower temperature $\left(T_{1}\right)$. This effect explains the behaviour of $\mathrm{Al}-\mathrm{Mg}-\mathrm{Si}$ alloys which show delayed ageing (Murali et al 1993) where room temperature storage $\left(T_{1}\right)$ gives rise to a coarse precipitate structure after artificial ageing $\left(T_{2}\right)$.

Now, considering the elastic strains between the cluster and the matrix, the modified Gibbs-Thomson relationship (11), Pashley's criterion $\left(A X_{\infty} S>B X\right.$ (i.e. (12)) for stability on clusters after two-step ageing can be expressed as

$$
A X_{\infty} S>B X_{\mathrm{i}, \infty} \exp \left(\frac{V_{\mathrm{m}} 2 \gamma}{R T r}+\frac{V_{\mathrm{m}} E \varepsilon^{2}}{4 R T}\right) .
$$

By substituting (11) in (12)

$$
\begin{aligned}
& \ln \left(\frac{A}{B}\right) S>\left(\frac{V_{\mathrm{m}} 2 \gamma}{R T r}+\frac{V_{\mathrm{m}} E \varepsilon^{2}}{4 R T}\right), \\
& r \ln \left(\frac{A}{B}\right) S>\left(\frac{V_{\mathrm{m}} 2 \gamma}{R T}+r \frac{V_{\mathrm{m}} E \varepsilon^{2}}{4 R T}\right) .
\end{aligned}
$$

Letting

$$
K=\frac{V_{\mathrm{m}} 2 r}{R T}, \quad Q=\frac{V_{\mathrm{m}} E \varepsilon^{2}}{4 R T},
$$

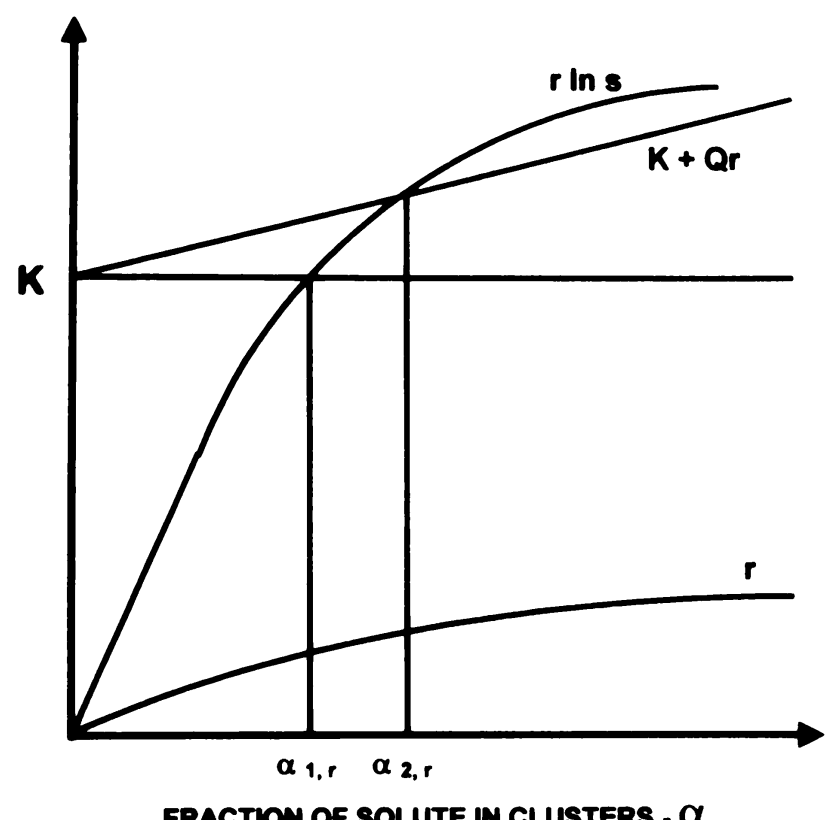

FRACTION OF SOLUTE IN CLUSTERS - $\alpha$

Figure 3. Schematic illustration of stability of clusters considering elastic strains.

$$
r \ln \left(\frac{A}{B}\right) S>K+Q r
$$

Equation (18) is thus the general stability criterion for clusters which introduce elastic strains in the matrix.

If it is assumed that there are no excess vacancies, $A=B$, then (18) becomes

$$
r \ln S>K+Q r
$$

Figure 3 shows the stability diagram for clusters after twostep ageing with $K$ and $K+Q r$. It is clearly shown in the figure that the clusters with $\alpha_{1, \mathrm{r}}$ get stabilized when no strain is considered in the matrix. On the other hand, when elastic strains are considered, a much longer delay representing a situation like $\alpha 2$, (where $\alpha 2, r \gg \alpha 1, r$ ) is required for the cluster to stabilize. Thus it can be stated that clusters will find it more difficult to stabilize with the introduction of coherency strains.

Figure 4 shows the effect of size distribution of clusters with increase in delay at $T_{1}$ (lower temperature) corresponding to increased $\alpha$. It can be seen from figure 4 that only the large sized clusters are stabilized at $\alpha_{r \text {,max }}$ in the original Pashley's model whereas with coherency strains such clusters are also destabilized. In the original model, such behaviour would have led to delayed ageing wherein a coarse precipitate structure is evolved upon delay. But with large coherency strains (large $Q$ ) delayed ageing is not expected.

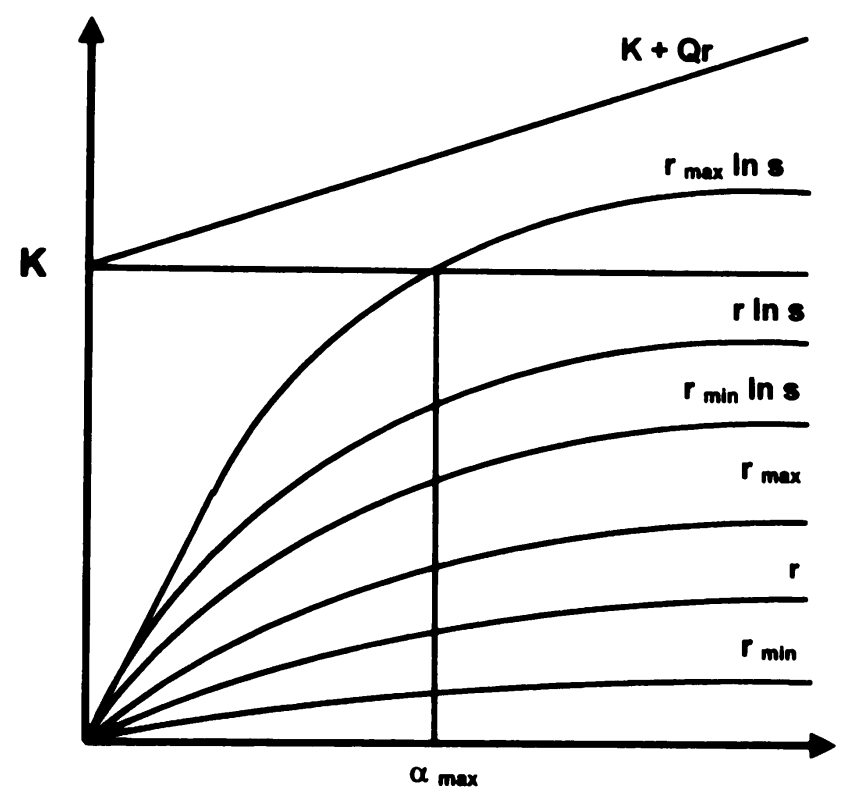

FRACTION OF SOLUTE IN CLUSTERS - $\alpha$

Figure 4. Schematic illustration of stability of clusters with size distribution considering elastic strains. 


\section{Experimental}

In order to test the extended Pashley's model, alloy AA 7010 was selected for delayed ageing studies. The composition of AA7010 is given in table 1.

Samples were sectioned and heat treated AA 7010 samples were solutionized at $748 \mathrm{~K}$ for $50 \mathrm{~min}$ and water quenched. The samples were delayed for $0,2,4,20$ and $68 \mathrm{~h}$ respectively and then artificially aged at $443 \mathrm{~K}$ for $24 \mathrm{~h}$. Samples were machined and tested for mechanical properties in an universal testing machine.

\section{Results and discussion}

Table 2 shows yield strength as a function of delay in artificial ageing for AA7010 alloy. There is no substantial drop in the tensile strength with delay in ageing. The percentage drop in the tensile strength is only $7.42 \%$ with $20 \mathrm{~h}$ delay whereas in $\mathrm{Al}-\mathrm{Mg}-\mathrm{Si}$ alloy (Murali et al 1993), the percentage drop in tensile strength is $15 \%$. Thus it can be seen that delayed ageing is more severe in $\mathrm{Al}-\mathrm{Mg}-\mathrm{Si}$ alloy.

To rationalize the above results, the following analysis was carried out. The elastic strain free energy is given by Eshelby (Cahn et al 1991) as,

$$
\Delta G_{\mathrm{el}}=2 G\left(\frac{1+v}{1-v}\right) \delta^{2},
$$

where, $G$ is the shear modulus, $v$, the Poisson ratio.

$$
\delta \text {, the misfit strain parameter }=\frac{a_{\mathrm{ppt}}-a_{\text {matrix }}}{a_{\text {matrix }}},
$$

$a_{\mathrm{ppt}}$ is the lattice parameter of the precipitate, $a_{\text {matrix }}$, the lattice parameter of the matrix.

To relate elastic strain in the matrix due to coherency strains between precipitate and matrix

$$
\begin{aligned}
& \frac{1}{2} \sigma \varepsilon=\Delta G_{\mathrm{el}}=2 G\left(\frac{1+v}{1-v}\right) \delta^{2} . \\
& \frac{1}{2} E \varepsilon^{2}=2 G\left(\frac{1+v}{1-v}\right) \delta^{2} .
\end{aligned}
$$

Table 1. Compositions of AA 7010 and LM25.

\begin{tabular}{lccccccccc}
\hline & \multicolumn{8}{c}{ Element } \\
\cline { 2 - 8 } & $\mathrm{Zn}$ & $\mathrm{Mg}$ & $\mathrm{Li}$ & $\mathrm{Cu}$ & $\mathrm{Zr}$ & $\mathrm{Si}$ & $\mathrm{Fe}$ & $\mathrm{Al}$ \\
\hline $\begin{array}{r}\text { AA 7010 } \\
\text { (wt \%) }\end{array}$ & $6 \cdot 2$ & 2.5 & - & 1.5 & - & - & - & $\mathrm{Bal}$ \\
$\begin{array}{r}\text { LM 25 } \\
\text { (wt \%) }\end{array}$ & - & 0.3 & - & - & - & 7.0 & 0.5 & Bal \\
\hline
\end{tabular}

Therefore,

$$
\varepsilon=\sqrt{\frac{4 G}{E}\left(\frac{1+v}{1-v}\right)} \delta
$$

It is known that,

$$
\begin{aligned}
& G=\frac{E}{2(1+v)}=26 \cdot 12 \mathrm{GPa} \text { for aluminium, } \\
& E=70 \mathrm{Gpa}, \\
& v=0 \cdot 34 .
\end{aligned}
$$

Table 3 shows the misfit strain calculations for intermediate precipitate based on the orientation relationship with the matrix for several aluminium alloys. From the values of misfit strain $(\delta)$, the corresponding elastic strains $(\varepsilon)$ have been evaluated using the relationship (20) and are recorded in table 3 . It can be seen that the misfit strain parameter for $\mathrm{Al}-\mathrm{Mg}-\mathrm{Si}$ alloy is very small whereas in $\mathrm{Al}-\mathrm{Zn}-\mathrm{Mg}$ alloy, it is very large. Similarly elastic strain ' $\varepsilon$ ' is large for $\mathrm{Al}-\mathrm{Zn}-\mathrm{Mg}$ and small for $\mathrm{Al}-\mathrm{Mg}-\mathrm{Si}$ alloy.

It should be noted from recent literature (Maloney et al 1999; Murayama and Hono 1999), that the chemistry of the GP zones by atom probe and field ion microscopy in $\mathrm{Al}-\mathrm{Zn}-\mathrm{Mg}$ and $\mathrm{Al}-\mathrm{Mg}-\mathrm{Si}$ alloys, respectively is determined. The composition of the GP zone in Al-Mg-Si

\begin{tabular}{|c|c|c|c|}
\hline Alloy & $\mathrm{Al}-\mathrm{Zn}-\mathrm{Mg}$ & $\mathrm{Al}-\mathrm{Mg}-\mathrm{Si}$ & $\mathrm{Al}-\mathrm{Cu}-\mathrm{Mg}$ \\
\hline $\begin{array}{l}\text { Intermediate } \\
\text { precipitate }\end{array}$ & $\eta^{\prime}$ & $\beta^{\prime}$ & $S^{\prime}$ \\
\hline $\begin{array}{l}\text { Orientation } \\
\text { relationship }\end{array}$ & $\begin{array}{l}(001) \eta^{\prime} \\
||(111) \alpha\end{array}$ & $\begin{array}{l}\text { (001) } \beta \\
||(100) \alpha\end{array}$ & $\begin{array}{l}(210)_{S} \\
||(100) S\end{array}$ \\
\hline $\begin{array}{l}\text { Misfit }(\delta) \% \\
\text { Elastic strain }(\varepsilon)\end{array}$ & $\begin{array}{c}-23 \cdot 75 \\
-0 \cdot 4134\end{array}$ & $\begin{array}{c}-7.4 \times 10^{-3} \\
-0.128 \times 10^{-3}\end{array}$ & $\begin{array}{c}-0.1216 \\
-2 \cdot 1 \times 10^{-3}\end{array}$ \\
\hline $\begin{array}{l}\eta^{\prime}\left(\mathrm{MgZn}_{2}\right) \\
\beta^{\prime}\left(\mathrm{Mg}_{2} \mathrm{Si}\right)\end{array}$ & $\begin{array}{l}\text { hexagonal } \\
\text { hexagonal }\end{array}$ & $\begin{array}{l}a=4.96 \AA \\
a=7.05 \AA\end{array}$ & $\begin{array}{l}c=8.68 \AA \\
c=4.05 \AA\end{array}$ \\
\hline $\mathrm{S}^{\prime}\left(\mathrm{Al}_{2} \mathrm{CuMg}\right)$ & orthorhombic & $\begin{array}{l}a=4.04 \AA \\
c=7 \cdot 18 \AA\end{array}$ & $b=9 \cdot 25 \AA$ \\
\hline
\end{tabular}
alloys is 50 at $\% \mathrm{Mg}, 50$ at\% Si. The composition of GP zone in $\mathrm{Al}-\mathrm{Zn}-\mathrm{Mg}$ alloy is given by 8.7 at\% $\mathrm{Zn}, 6.3$ at\% $\mathrm{Mg}$ giving a ratio of $\mathrm{Zn}: \mathrm{Mg}$ of 1.4 : 1 .

Table 2. Effect of delay in ageing on the tensile strength of AA 7010 alloys.

\begin{tabular}{cccccc}
\hline & \multicolumn{2}{c}{$\begin{array}{c}\text { Alloy 7010 } \\
(\mathrm{Al}-\mathrm{Zn}-\mathrm{Mg})\end{array}$} & & \multicolumn{2}{c}{$\begin{array}{c}\text { LM 25 } \\
\text { (Al-Mg-Si })\end{array}$} \\
\cline { 2 - 3 } \cline { 5 - 6 } $\begin{array}{l}\text { Delay } \\
\text { (h) }\end{array}$ & $\begin{array}{c}\text { YS } \\
\text { (Mpa) }\end{array}$ & $\begin{array}{c}\text { \% Red. } \\
\text { (UTS })\end{array}$ & & $\begin{array}{c}\text { YS } \\
(\mathrm{Mpa})\end{array}$ & $\begin{array}{c}\text { \% Red. } \\
\text { (UTS) }\end{array}$ \\
\hline 0 & 512 & - & & 230 & - \\
20 & 474 & $7 \cdot 42$ & & 195 & $15 \cdot 2$ \\
\hline
\end{tabular}

Table 3. Misfit strain values. 
Table 4. Misfit strain values (GP zones).

\begin{tabular}{lcl}
\hline Alloy & $\mathrm{Al}-\mathrm{Mg}-\mathrm{Si}$ & $\mathrm{Al}-\mathrm{Zn}-\mathrm{Mg}$ \\
\hline Volume per atom & $24.09 \AA^{3}$ & $31.136 \AA^{3}$ \\
Volume per atom (matrix) & $24.60 \AA^{3}$ & $29.520 \AA^{3}$ \\
Misfit $\delta$ & 0.02073 & -0.0597 \\
\hline
\end{tabular}

Taking atomic ratio of $\mathrm{Al}, \mathrm{Mg}, \mathrm{Si}, \mathrm{Zn}$, the volume per atom of the GP zones is calculated. Table 4 shows results of the calculation. It is seen the misfit strain (difference between volume/atom of zones and matrix) is low $(0.02073)$ for Al-Mg-Si alloy whereas it is high for Al$\mathrm{Zn}-\mathrm{Mg}$ alloy (-0.0547). Using (20) the elastic strain is also calculated. It is also shown in table 4.

From the model, the stability criterion for clusters after two-step ageing is given by the following equation

$$
r \ln S>K+Q r
$$

where,

$$
K=\frac{2 \gamma V_{\mathrm{m}}}{R T}, \quad Q=\frac{E \varepsilon^{2}}{4 R T},
$$

$Q$ is a dimensionless quantity whereas $K$ has units of length.

Assuming, $V_{\mathrm{m}}=10^{-5} \mathrm{~m}^{3} / \mathrm{mole}, \gamma=0.5 \mathrm{~J} / \mathrm{m}^{2}$ (typical surface energy), $R=8 \cdot 31 \mathrm{~J} / \mathrm{mole}^{-1} \mathrm{~K}^{-1}, T=453 \mathrm{~K}$ (typical artificial ageing temperature) $K=2.65 \mathrm{~nm}, Q$ has been calculated for $\mathrm{Al}-\mathrm{Zn}-\mathrm{Mg}$ and $\mathrm{Al}-\mathrm{Mg}-\mathrm{Si}$ alloys while $Q$ for $\mathrm{Al}-\mathrm{Zn}-\mathrm{Mg}$ alloys comes to a large value of 7.94 , it is a very low value of $7.61 \times 10^{-7}$ for $\mathrm{Al}-\mathrm{Mg}-\mathrm{Si}$ alloy.

Using the elastic strain from table $4, Q$ has been calculated for $\mathrm{Al}-\mathrm{Mg}-\mathrm{Si}$ and $\mathrm{Al}-\mathrm{Zn}-\mathrm{Mg}$ alloys. It comes to $2.9194 \times 10^{-4}$ for $\mathrm{Al}-\mathrm{Mg}-\mathrm{Si}$ whereas $7.7 \times 10^{-4}$ for $\mathrm{Al}-\mathrm{Zn}-\mathrm{Mg}$.

This calculation reveals that the trend of increasing $Q$ and $\mathrm{Qr}$ values from $\mathrm{Al}-\mathrm{Mg}-\mathrm{Si}$ alloy to $\mathrm{Al}-\mathrm{Zn}-\mathrm{Mg}$ alloy is consistent with the calculation of the same quantities for intermediate precipitates.

A reasonable assumption for cluster size would be $r=10 \mathrm{~nm}(100 \AA)$. The term ' $Q r$ ' is calculated for $\mathrm{Al}-\mathrm{Zn}-\mathrm{Mg}$ and $\mathrm{Al}-\mathrm{Mg}-\mathrm{Si}$ alloys. $\mathrm{Qr}$ for $\mathrm{Al}-\mathrm{Zn}-\mathrm{Mg}$ alloy comes to $7.94 \mathrm{~nm}$ whereas for $\mathrm{Al}-\mathrm{Mg}-\mathrm{Si}$ it is only $76 \cdot 1 \times 10^{-7} \mathrm{~nm}$.

Now the modified stability diagram is schematically shown in figure 5 . It can be seen from the figure that clusters are destabilized for $\mathrm{Al}-\mathrm{Zn}-\mathrm{Mg}$ alloy after twostep ageing whereas they would be stabilized for $\mathrm{Al}-\mathrm{Mg}-$ Si alloy.

This explains how the coarse clusters are stabilized at the artificial ageing temperature in $\mathrm{Al}-\mathrm{Mg}-\mathrm{Si}$ alloys and

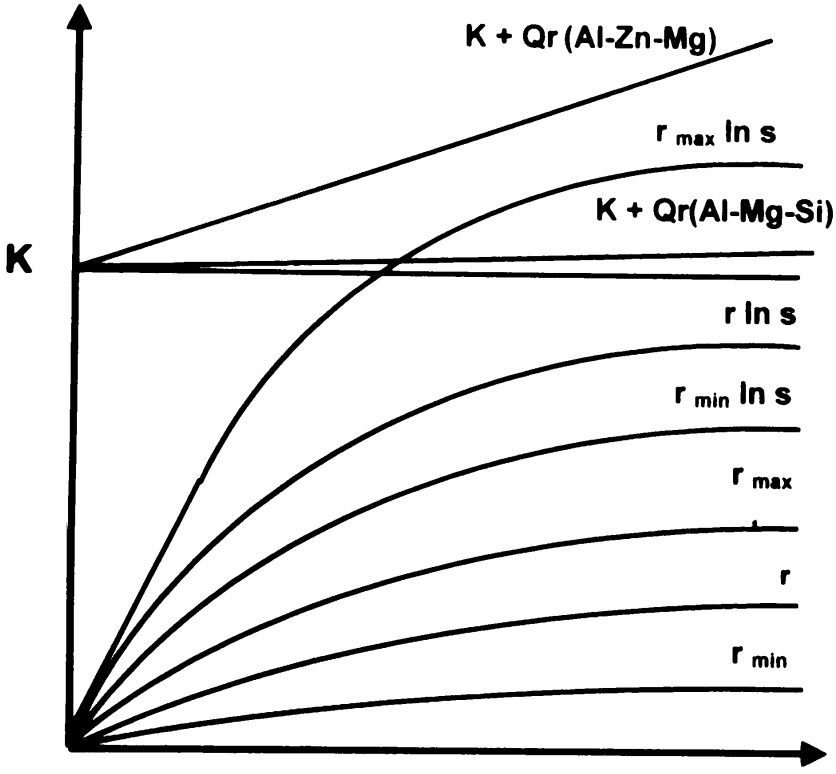

FRACTION OF SOLUTE IN CLUSTERS - $\alpha$

Figure 5. Schematic illustration of stability situation for $\mathrm{Al}-\mathrm{Mg}-\mathrm{Si}$ and $\mathrm{Al}-\mathrm{Zn}-\mathrm{Mg}$ alloys.

thus results in lower mechanical properties as observed. However in the case of $\mathrm{Al}-\mathrm{Zn}-\mathrm{Mg}$ alloys the clusters are destabilized however large they are because of large $\mathrm{Qr}$ and this results in fine and uniform precipitation of $\eta^{\prime}$ at the artificial ageing temperature leading to insignificant drop in mechanical properties.

\section{Conclusions}

(I) A term to consider the effects of coherency strains between cluster and matrix has been successfully incorporated in the original Pashley's model.

(II) Experimental results show an insignificant drop in mechanical properties for AA 7010 .

(III) The high coherency strain between the cluster and matrix has been shown to be responsible for the reduction of delayed ageing in AA7010 alloy. It is also argued that low coherency strain between the cluster and matrix is the reason for delayed ageing in $\mathrm{Al}-\mathrm{Mg}-\mathrm{Si}$ alloy.

(IV) According to the extended Pashley's model developed in the present study, cluster stability definitely gets affected due to elastic coherency strains in the matrix. The prediction of the new model has been verified.

\section{Acknowledgement}

The authors wish to thank the management of Hindustan Aeronautics Ltd., Bangalore for support. 


\section{References}

Cahn R W, Haasen P and Kramer E J (eds) 1991 Phase transformation in materials, A comprehensive treatment (New York: VCH Publications) Vol. 5

Fast J D 1970 Entropy (Holland: Philips Technical Library) p. 91 Ghate G P, Murthy K S S and Raman K S 1984 Aluminium 60 18

Lorimer O and Nicholson R B 1966 Acta Met. 191009
Maloney S K, Hono K, Polemar I J and Ringer S P 1999 Scr. Met. 411031

Murali S, Kashyap K T, Raman K S and Murthy K S S 1993 Scr. Met. 291421

Murayama M and Hono K 1999 Acta Met. (in press)

Pashley D W, Rhodes J W and Sendorek A 1966 J. Inst. Met. 9441

Pashley D W, Jacobs M A and Vietz J T 1967 Philos. Mag. 1651

Porter D A and Easterling K E 1992 Phase transformations in metals and alloys (UK: Chapman \& Hall) p. 46 